\title{
A mudança lexical em Libras: um estudo preliminar em Goiás
}

\author{
Lexical change in Libras: a preliminary study in Goiás
}

El cambio lexical en Libras: un estudio preliminar en Goiás

\author{
iD (9) Leandro Viana Silva \\ Instituto Federal de Educação, Ciência e Tecnologia do Rio Grande do Norte (IFRN), \\ Natal, Rio Grande do Norte, Brasil. \\ E-mail: leandrovianna21@gmail.com
}

iD Sheila de Carvalho Pereira Gonçalves

Universidade Federal de Catalão (UFCAT), Catalão, Goiás, Brasil.

E-mail: sheilacpgoncalves@outlook.com

Resumo: Pesquisas sobre a manifestação do fenômeno da variação e da mudança segundo aspectos sociais e linguísticos na Libras ainda são limitadas. O objetivo deste artigo é realizar um estudo sobre a mudança lexical da Libras a partir de antigos registros retirados de materiais didáticos de duas instituições de ensino, na cidade de Goiânia - Goiás. Esta pesquisa, de cunho qualitativo, tem como base teórica principal os trabalhos de Diniz (2010), Campello (2011), Nascimento e Correia (2011), Xavier (2014) e Lima e Rezende (2016). Os resultados finais demonstram que todos os sinais da categoria mudança lexical que constituem o léxico da Libras manifestaram alguma alteração em seus léxicos.

Palavras-chave: Libras. Mudança lexical. Goiás.

\begin{abstract}
Researches about variation and change phenomena according to social and linguistic aspects in Libras are still limited. This article aims to develop a study about lexical change in Libras from old records taken from teaching materials from two educational institutions from the city of Goiânia, Goiás. This qualitative research has as its main theoretical
\end{abstract}


basis the works of Diniz (2010), Campello (2011), Nascimento and Correia (2011), Xavier (2014) and Lima and Rezende (2016). The results indicate that all signs of the lexical change category manifested some occurrence of change in their lexis.

Keywords: Libras. Lexical change. Goiás.

Resumen: Investigaciones sobre la manifestación del fenómeno de variación y cambio según aspectos sociales y lingüísticos en Libras aún son limitados. El propósito de este artículo es realizar un estudio sobre el cambio léxico en Libras a partir de registros antiguos extraídos de materiales didácticos de dos instituciones educativas, en la ciudad de Goiânia-Goiás. Esta investigación, de carácter cualitativo, tiene como principal base teórica los trabajos de Diniz (2010), Campello (2011), Nascimento y Correia (2011), Xavier (2014) y Lima y Rezende (2016). Los resultados finales demuestran que todas las señales de la categoría de cambio lexical manifestaron alguna ocurrencia de cambio en sus léxicos.

Palabras clave: Libras. Cambio lexical. Goiás.

Submetido em 30 de abril de 2020.

Aceito em 12 de outubro de 2020.

Publicado em 07 de maio de 2021. 


\section{Introdução}

Na Libras, assim como em qualquer outra língua, é natural a manifestação dos fenômenos da variação e da mudança, segundo variáveis sociais e linguísticas. No entanto, ainda há poucas pesquisas publicadas no âmbito da Sociolinguística que visem analisar e descrever a manifestação desses fenômenos.

De modo geral, para que a mudança efetivamente aconteça, é necessário um período em que as velhas e novas formas da língua coexistam, o que pode, como consequência, acarretar na mudança, conforme afirmam Weinreich et al. (2006, p. 139), as "velhas e novas formas variantes rivalizam num mesmo momento de tempo e essa alternância pode representar uma transição para um outro estado da língua". Nesse sentido, qualquer que seja a mudança, esta pressupõe a variação. Quer dizer que, para que efetivamente a mudança sobrevenha, a língua necessariamente deve passar por uma fase em que há variação e que coexistam duas ou mais variantes (CHAGAS, 2012).

Para Schmitt (2013) e Camacho (1988), há uma tendência que as formas antigas, e mesmo as formas em desuso, fiquem confinadas ao uso das gerações mais velhas, isto é, falantes mais velhos costumam ser mais conservadores. Desse modo, entendemos que as gerações mais jovens são mais adeptas à utilização de formas novas. O que pode, finalmente, eleger-se "como variante normal na fala da comunidade, com a eliminação completa da forma em substituição" (CAMACHO, 1988, p. 30), caracterizando assim uma mudança lexical.

A presente pesquisa tem por objetivo analisar a mudança lexical dos sinais na Libras, considerando-se os registros de duas instituições de ensino, que são detalhadas a seguir, na busca de identificarmos traços de motivações (quando possível) por trás dos signos, como a tendência de redução dos itens lexicais dos sinais compostos e do processo de duplicação das mãos. Adotaremos nesta pesquisa, o sistema brasileiro de Escrita das Línguas de Sinais - ELiS 
para registrar e realizar nossa análise, uma vez que a estrutura dos sinais nele representada é mais claramente percebida.

As instituições por nós escolhidas foram: o sistema educacional Chaplin, primeira instituição a oferecer o curso de Libras no estado de Goiás, entidade particular, criada pelo professor Edson Gomes (surdo) e que está ativa até os dias de hoje; e a Associação dos Surdos de Goiânia (ASG), instituição fundada em 1975, sem fins lucrativos, tendo como seu principal intuito a colaboração mútua, a prática de esportes, cultura e filantropia entre os seus membros; doravante Chaplin e ASG.

Organizamos assim o presente artigo que se divide em quatro partes, além desta introdução. Na primeira parte, expomos nossa fundamentação teórica, abordando, inicialmente, a mudança lexical na Libras e alguns aspectos decorrentes da mudança. $\mathrm{Na}$ segunda parte, detalhamos nosso corpus e metodologia, para, na terceira parte, apresentarmos nossas análises, seguidas das considerações finais e referências bibliográficas.

\section{Apontamentos teóricos}

No Brasil, as pesquisas que tratam dos fenômenos da variação e da mudança linguística na Libras, de acordo com Diniz (2010), Campello (2011), Castro Júnior (2011); Zancanaro Júnior e Bieleski (2011) e Lima e Rezende (2016), ainda são limitadas. Apesar de serem em número reduzido, essas pesquisas, não diferente das línguas orais, mostram que a língua de sinais também apresenta esse fenômeno, pois a língua de sinais possui variações e mudanças como qualquer outra língua natural.

Karnopp (2008, p. 6), em suas pesquisas sobre a Libras, reconhece que "a linguística, ao estudar qualquer comunidade que usa uma língua, constata, de imediato, a existência de diversidade ou de variação, ou seja, a comunidade linguística (no caso aqui investigada, a comunidade de surdos) se caracteriza pelo emprego de diferentes modos de usar a língua de sinais". 
A mudança lexical em Libras: um estudo preliminar em Goiás

Leandro Viana Silva • Sheila de Carvalho Pereira Gonçalves

Um fator que merece destaque é que as variações podem ser esperadas tanto na contraposição entre jovens e idosos de uma comunidade, quanto em relação à fase de início de exposição à língua de sinais. Esse último, diz respeito ao período de aquisição da língua de sinais, pois, em casos de surdos, filhos de pais ouvintes, isso pode variar e, por conseguinte, ter grandes interferências no uso da língua. Esse início de aquisição pode acontecer logo após o nascimento - que será um surdo nativo da língua de sinais -, ou precocemente, ou tardiamente (CASTRO JÚNIOR, 2011).

A variação e a mudança linguística, na Libras, podem ser observadas em diversas dimensões. Zancanaro Junior e Bieleski (2011), ao analisarem o nível fonológico da Libras, esclarecem que as mudanças que afetam o léxico das línguas orais são notadas/ analisadas através do som, ao passo que nas línguas de sinais, por não utilizarem o som das palavras, as mudanças fonológicas são analisadas com base nas mãos, melhor dizendo, como a(s) mão(s) está/estão configurada(s), lugar em que ela(s) está/estão sendo articulada(s), a posição de sua(s) palma(s) e o(s) seu(s) movimento(s).

Zancanaro Junior e Bieleski (2011) pesquisam o assunto e fazem uma análise comparativa de sinais na Libras em dois dicionários $^{1}$. Os autores apresentam vários exemplos, dentre eles, escoIhemos o que foi classificado como mudança lexical e que pode ser observado na Figura 1, a seguir:

Figura 1 - Sinal de CAFÉ nas obras: (a) Iconographia de Signaes e (b) UDESC

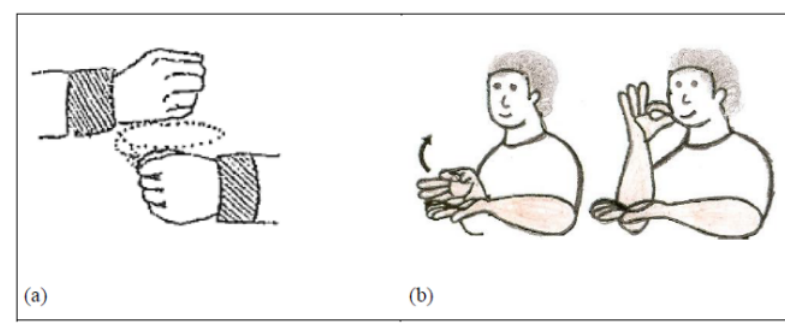

Fonte: Zancanaro Junior e Bieleski (2011, p. 66)

1 Os dicionários utilizados na pesquisa foram Iconographia dos Signaes de 1875 e Dicionário Digital de Libras da Universidade do Estado de Santa Catarina (UDESC) de 2002. Segundo os autores, o primeiro possui gravuras que são facilmente visualizadas e com possibilidade de impressão. Já o segundo, por ser digital, está disponível apenas em vídeo, o que torna difícil a visualização na forma impressa, assim sendo, os autores fizeram algumas adaptações nas imagens. 
Podemos depreender na Figura 1 que o sinal de CAFÉ apresenta mudança lexical, uma mudança em toda a forma do sinal. Notamos que, enquanto o sinal de CAFÉ no dicionário (a) Iconographia de Signaes apresenta disposição das mãos fechadas, na horizontal, palmas para dentro, a mão esquerda parada e a mão direita com movimento circular horizontal, o dicionário (b) UDESC articula: mão esquerda aberta na horizontal, mão direita com dedos indicador e polegar unidos pelas pontas e demais dedos estendidos, e se move ligeiramente em direção à boca.

Os dois dicionários, tanto o Iconographia de Signaes, de 1875, como o UDESC, de 2002, Zancanaro Junior e Bieleski (2011), são enfáticos ao dizer que, com base em suas análises, as mudanças dos sinais são bastante significativas, pois atestam que são usados poucos sinais idênticos aos de 1875. Atentando-se às duas representações expostas pelos autores, percebemos que o sinal de CAFÉ do dicionário (a) Iconographia de Signaes foi inteiramente motivado pela ação de moer os grãos de café manualmente em máquina da época, como podemos ver, a seguir, na Figura 2.

Figura 2 - Antiga máquina para moer café

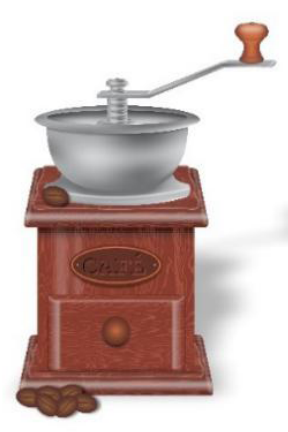

Fonte: Discovery Center. Disponível em: https://learn.corel.com/contest-entry/antiga-maquina-para-moer-cafe/ Acesso em: 24 mai. 2018.

Já no dicionário (b) UDESC notamos que, ao longo dos anos, o sinal foi modificado, passando a reproduzir não mais a ação de moer os grãos na máquina, mas sim, a ação de tomar o café, simbolizando com uma mão a base que representa o 'pires' e, com a 
A mudança lexical em Libras: um estudo preliminar em Goiás

Leandro Viana Silva • Sheila de Carvalho Pereira Gonçalves

outra mão, a simulação de segurar a asa de uma xícara. Podemos conferir, a seguir, na Figura 3, os traços motivacionais para o sinal usado atualmente:

Figura 3 - Pires e xícara de café

Fonte: Tenvinilo. Disponivel em: https://www.tenvinilo.co/vinilos-decorativos/vinilo-decorativo-tazon-cafe-con-leche-1665. Acesso em: 24 mai. 2018.

Com base nesses exemplos das Figuras 2 e 3, reiteramos a afirmação de Kogut que, cada sociedade "seleciona um aspecto que será mais evidente para representar em seus sinais [...] sob uma determinada ótica ou perspectiva" (KOGUT, 2015, p. 50, grifo nosso). Nesses casos, os referidos sinais foram ora motivados pela ação de moer os grãos de café manualmente na máquina, ora motivados pela ação de tomar café.

As motivações estão fortemente ligadas à cultura, a um período específico, o que torna cada item lexical absolutamente significativo à sua época. Nesse caso, vimos que a criação do sinal tende naturalmente a se aproximar da realidade, do contexto do falante. Atualmente, por exemplo, a comunidade surda pode, inclusive, desconhecer o sinal de CAFÉ registrado no dicionário Iconographia de Signaes, pois, tal prática - de moer manualmente os grãos - se distancia da realidade atual dos usuários da Libras, que utilizam o café moído industrializado. Nesse sentido, a Libras, como as outras línguas, sofre mudanças ao longo do tempo em seus símbolos linguísticos, consciente ou inconscientemente, de acordo com as necessidades e interesses dos falantes. 


\subsection{Alguns aspectos decorrentes da mudança}

No processo de (re)criação dos símbolos linguísticos na língua de sinais, há, além da interferência cultural, a interferência da Língua Portuguesa na Libras. À vista disso, Diniz (2010) relata que no processo de mudança de um sinal pode haver várias interferências e uma delas é o empréstimo de palavras/sinais de uma língua para outra. Processo bastante comum entre as línguas que possuem contato entre falantes de línguas ou culturas distintas.

De acordo com Diniz (2010, p. 48) "as interferências do Português na Libras são regularizadas, ao longo do tempo, mesmo que isso implique uma diminuição da iconicidade do sinal, em direção à arbitrariedade". Em outras palavras, o resultado desse contato, 0 empréstimo linguístico, pode não ser tão facilmente notado pelos falantes, o que implica, às vezes, em dificultar sua identificação.

O alfabeto manual usado na Libras, por exemplo, é um empréstimo das letras do alfabeto brasileiro, ou seja, as CMs utilizadas no alfabeto manual da Libras correspondem às letras do nosso alfabeto. A partir dessas CMs, há um processo comum, a criação de sinais com base no empréstimo das letras do alfabeto, conhecidos como sinais inicializados. Esses são sinais "motivados pela 'importação' da letra inicial da palavra equivalente em língua portuguesa. Essa letra será a CM utilizada para a articulação do item designado" (NASCIMENTO; CORREIA, 2011, p. 67).

Nascimento e Correia (2011, p. 66) afirmam que a criação de sinais a partir de empréstimos das letras do nosso alfabeto é bastante comum nas línguas de sinais. Essa criação "por meio do empréstimo, apenas, da inicial da palavra da língua oral, [é] totalmente adaptada e apropriada pela língua de sinais receptora, para a articulação do item lexical". Esse processo seria mais próximo para nós, em português, do que conhecemos como aportuguesar, isto é, adaptar palavras oriundas de outros idiomas para a Língua Portuguesa, adaptação de níveis estruturais, fonético, fonológico, morfológico etc. 
A mudança lexical em Libras: um estudo preliminar em Goiás

Leandro Viana Silva · Sheila de Carvalho Pereira Gonçalves

A esse respeito, Diniz (2010) apresenta um caso de mudança lexical por meio do empréstimo. A autora exemplifica que a palavra "e-mail", emprestada do inglês para o português, já sofreu um processo de regularização fonológica, sendo pronunciada como "emeio" ou "imeio". Posteriormente, a palavra, já adaptada no Português, foi emprestada para a Libras, que inicialmente possuía configurações de mão em " $E$ " e " $M$ ", mão esquerda e direita, respectivamente (em relação à sinalizadora), com o movimento da mão direita sendo realizada no "meio" da mão esquerda, iconicamente ${ }^{2}$ representando a palavra "meio" do Português. Veja a seguir, na Figura 4, a mudança lexical das formas do sinal E-MAIL:

Figura 4 - O processo de mudança do sinal E-MAIL

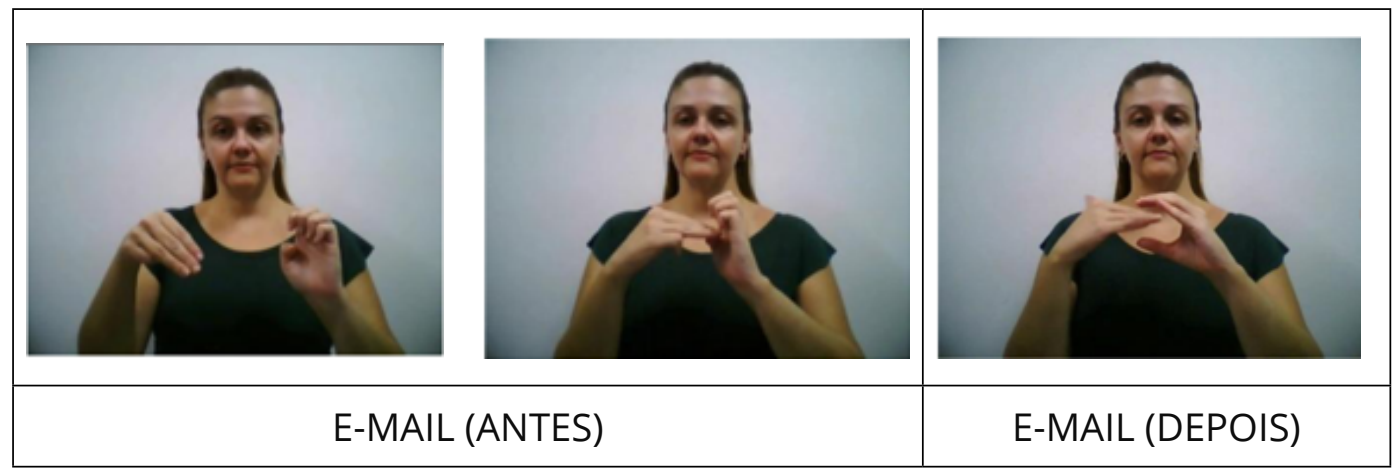

Fonte: Diniz (2010, p.47, adaptado)

A mudança lexical também foi objeto de estudo de Campello (2011). A autora realiza uma pesquisa a fim de averiguar as mudanças nos léxicos da Libras, ocorridas em 1857, 1875, 1969 e 2002, em que se pode verificar nitidamente a modificação do sinal VACA, como mostra, a seguir, a Figura 5.

2 Iconicidade tem por fundamento a ideia de uma motivação que se reflete na estrutura das palavras (língua oral) ou dos sinais (língua de sinais). Dessa forma, o sinal icônico deve ser motivado por algo no mundo real, de modo que sua produção remeta ao referente. 
A mudança lexical em Libras: um estudo preliminar em Goiás

Leandro Viana Silva • Sheila de Carvalho Pereira Gonçalves

Figura 5 - Sinal VACA em diferentes épocas

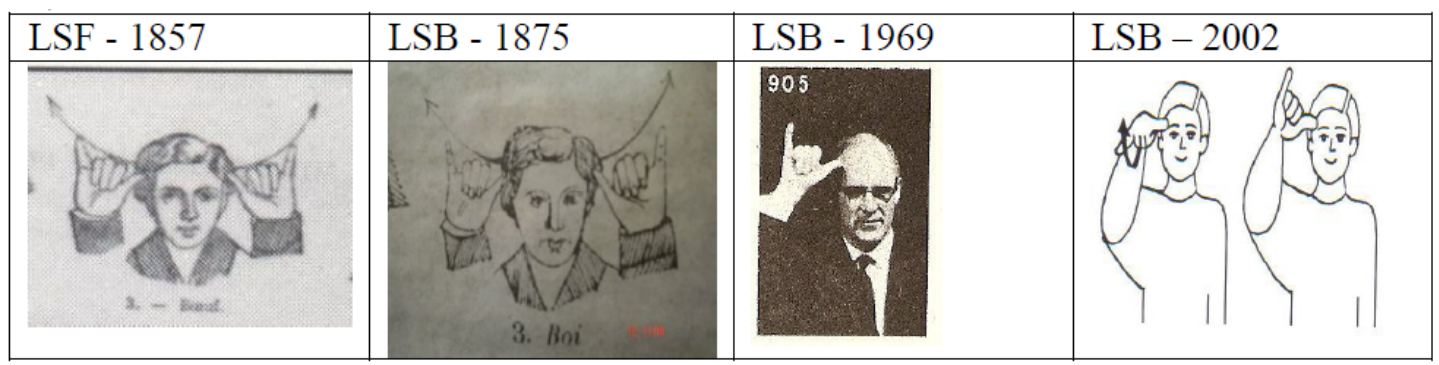

Fonte: Campello (2011, p. 22)

Note que, nos dois primeiros registros, LSF-1857 e LSB - 1875³, ambos apresentam igualdade em suas formas (sinais bimanuais simétricos), ao passo que os dois últimos, LSB - 1969 e LSB - 2002, exibem formas similares, distinguindo-se, apenas, pelo movimento do sinal e, sendo realizado com somente uma das mãos (sinais monomanuais). Características como estas podem ser observadas no processo de mudança lexical, isto é, sinais que em princípio suas produções envolviam ambas as mãos e que passaram a ser realizados com apenas uma mão (LIMA; REZENDE, 2016).

O processo de duplicação das mãos é outro ponto que também merece atenção. Esse processo que duplica as mãos em sinais realizados antes com apenas uma mão, não acontece de forma aleatória, há pelo menos dois fatores que podem bloqueá-lo. Segundo Xavier (2014), esse processo somente pode acontecer quando: (i) o sinal não possuir movimento alternado; e, (ii) no sinal não houver contato entre as duas mãos. Esses fatores podem bloquear o processo de duplicação, casos contrários a esses são normalmente duplicados. A título de exemplo desse processo de duplicação das mãos, temos os sinais: AGORA, COISAS e DESCANSAR.

Outro grande destaque são os sinais expressos por composição que, compostos por dois ou mais itens lexicais, adquirem novos conceitos. Nascimento e Correia (2011), Diniz (2010) e Lima e Rezende (2016) observaram algumas tendências nas composições na Libras no decorrer dos anos. Os autores notaram que há

3 LSF é a abreviação de Língua de Sinais Francesa, e, LSB é correspondente à Libras. A autora justifica que a utiliza por uma questão das regras internacionais para denominar a língua de sinais dos surdos. 
certa recorrência de redução dos itens lexicais nas composições. Exemplos de sinais que tiveram redução de itens: BANHEIRO, ADVOGADO e COBRA.

Para Nascimento e Correia (2011, p. 69), por exemplo, o sinal antes expresso por composição, assume uma nova forma, perdendo as características de sinal composto. É visto como tendência dos falantes da Libras, o processo de assimilar lexias complexas, tornando-as itens lexicais únicos. Essas mudanças/reduções nos sinais podem se dar pela necessidade de se comunicar com mais celeridade, tais características podem se basear no princípio de economia.

Diniz (2010, p. 92) também verifica a recorrência de redução dos sinais compostos e afirma que "é o tipo de tendência, no qual os sinais compostos se transformam para unitários". Nas menções de Nascimento e Correia (2011), e agora de Diniz (2010), observa-se que as autoras sempre fazem referências às reduções com perda da característica de composição, ou seja, reduzem suas formas tornando-se um único item lexical, ou ainda, transformando-se em sinal unitário.

Os autores Lima e Rezende (2016) seguem o mesmo formato apresentado por Nascimento e Correia (2011), e por Diniz (2010), de que sinais compostos podem ser reduzidos a sinais de uma única lexia. Porém, os autores apresentam o processo de redução para um item apenas aos sinais que são formados por dois itens lexicais que tendem a reduzir sua composição a um único item, sem preservar, em alguns casos, as características de composição dos dois itens que, anteriormente, formavam o sinal.

Lima e Rezende (2016), mais adiante, apresentam outra redução, diferente daquelas expostas por Nascimento e Correia (2011) e Diniz (2010). Seria a redução aplicada aos sinais compostos por três itens lexicais que passam a operar com dois, excluindo, geralmente, o último item que integra a composição. Os autores sugerem ainda que, nos sinais compostos por três itens, diante de um item que representa a dimensão da entidade, o item que repre- 
A mudança lexical em Libras: um estudo preliminar em Goiás

Leandro Viana Silva • Sheila de Carvalho Pereira Gonçalves

senta a dimensão pode, com o passar do tempo, ser excluído, sem prejuízo no sentido do sinal e, acrescentam que, nesses casos, a representação do tamanho e da forma da entidade é uma informação secundária.

Abordamos nesta seção os fundamentos teóricos que embasam nosso trabalho. Passemos, a seguir, à apresentação de nosso corpus, a seleção das unidades lexicais, os participantes, os procedimentos de coleta e análise dos dados, o registro no ELiS, bem como, nossas análises.

\section{Nosso corpus}

Para a realização deste trabalho, tomamos como ponto de partida as coleções de Libras do Chaplin e da ASG. Ambas as coleções são utilizadas como materiais didáticos para o ensino de Libras nos cursos oferecidos nas duas instituições que têm como público-alvo pessoas ouvintes e surdas de diferentes faixas etárias.

Na procura do registro mais antigo das instituições, encontramos obras com um intervalo de 12 (doze) anos entre uma e outra. 0 Chaplin com seu acervo datado em 1994 e a ASG datado em 2006. Ambos os acervos são constituídos por 4 (quatro) volumes, que abrangem desde o Libras I até o Libras IV, e seus campos temáticos são metodizados com sinalários ${ }^{4}$, que apresentam a representação do sinal (em desenho) e, abaixo desta representação, a tradução para a Língua Portuguesa (em glosa), respectivamente.

Com base nos volumes que constituem essas coleções, nosso estudo está centrado nos volumes I, II, III. O volume IV não foi incluído porque não conseguimos o exemplar disponível no Chaplin e preferimos, assim, não incluir também o volume IV da ASG. Portanto, nosso corpus consta das seguintes obras: OLIVEIRA, Francisco Ferreira de. (Ed.). Libras I. ed. rev. Goiânia: [s.n.], 2006. OLIVEIRA, Francisco Ferreira de. (Ed.). Libras II. ed. rev. Goiânia: [s.n.], 2006. OLIVEIRA, Francisco Ferreira de. (Ed.). Libras III. ed.

4 Sinalário: conjunto de expressões que compõe o léxico de uma determinada língua de sinais (STUMPF, 2005, p. 36). 
rev. Goiânia: [s.n.], 2006. GOMES, Edson Franco; GOMES, Dalson Borges. Língua Brasileira de Sinais (LIBRAS) - Nível I. Goiânia: [s.n.], 1994. GOMES, Edson Franco; GOMES, Dalson Borges. Língua Brasileira de Sinais (LIBRAS) - Nível II. Goiânia: [s.n.], 1994. GOMES, Edson Franco; GOMES, Dalson Borges. Língua Brasileira de Sinais (LIBRAS) - Nível III. Goiânia: [s.n.], 1994.

\subsection{Seleção das unidades lexicais}

Após selecionarmos o corpus da pesquisa, percorremos todos os volumes, registrando em planilha cada um dos sinais e, para cada sinal, inserimos as seguintes informações: sinal, página, volume, mãos, itens lexicais e instituição, como disposto no Quadro 1 , a seguir.

Quadro 1 - Planilha com registro de informações dos sinais

\begin{tabular}{|c|c|c|c|c|c|}
\hline SINAL & PÁGINA & VOLUME & MÃOS & ITENS LEXICAIS $=$ & INSTITUIÇÃO \\
\hline CADEIRA & 37 & 1 & 1 & 1 & ASG \\
\hline CADEIRA & 11 & 2 & 1 & 1 & CHAPLIN \\
\hline CADERNO & 28 & 1 & 2 & 1 & ASG \\
\hline CAFE & $6[1]$ & 3 & 2 & 1 & CHAPLIN \\
\hline CAFÉ & 65 & 2 & 1 & 1 & ASG \\
\hline CAFÉ & 68 & 2 & 2 & 1 & CHAPLIN \\
\hline CAIR & 106 & 2 & 2 & 1 & ASG \\
\hline CAIR (2) & 45 & 2 & 2 & 1 & CHAPLIN \\
\hline CAJU & 44 & 1 & 1 & 1 & CHAPLIN \\
\hline CALÇA & 43 & 1 & 2 & 1 & ASG \\
\hline CALÇA & 10 & 2 & 2 & 1 & CHAPLIN \\
\hline$-\cdots$ & - & & & -- \\
\hline
\end{tabular}

Fonte: Elaborado pelos autores (2020).

É possível visualizar que, na coluna 1, o nome do sinal em glosa, ao lado, na coluna 2, a página do registro, na coluna 3, o volume em que se encontra, na coluna 4 , temos a quantidade de mãos usadas para a realização do sinal, na coluna 5, a quantidade de itens lexicais do sinal e, na coluna 6 , sinalizamos a instituição na qual o sinal aparece. 
Em seguida, realizamos um levantamento das unidades lexicais que sofreram mudanças, tanto as que poderiam contrapor os sinais contidos nas duas obras, como de sinais utilizados atualmente. Para tanto, nesse último caso, tomamos por base nosso conhecimento empírico da Libras, embasado na nossa experiência adquirida como tradutor e intérprete e nosso contato com os surdos usuários da língua de sinais, pois, nesse contexto, diariamente notamos a presença da mudança na forma de várias unidades léxicas.

Ao término do registro de todos os sinais na planilha, ordenamos por ordem alfabética, considerando as entradas em glosas. Assim sendo, resultamos em 930 (novecentas e trinta) entradas dos volumes da ASG e 794 (setecentas e noventa e quatro) entradas dos registros do Chaplin, totalizando 1.724 (mil setecentas e vinte e quatro) entradas.

Em seguida, filtramos as entradas que se repetiam em ambas as coleções, as quais computaram um total de 329 (trezentas e vinte e nove) entradas que apareceram tanto no Chaplin como na ASG. Tivemos também algumas entradas que apareceram exclusivamente no Chaplin, 465 (quatrocentas e sessenta e cinco) entradas, outras unicamente na ASG, 601 (seiscentas e uma) entradas.

Posteriormente, selecionamos os sinais que apresentaram qualquer mudança em suas formas, quer fosse uma contraposição das duas obras e/ou em relação aos sinais usados hoje. As mudanças compreendiam alterações em suas formas, fonológicas e morfológicas, sejam parciais ou totais, redução dos compostos e acréscimos de itens lexicais. Destacamos também sinais que se mantiveram ao longo do tempo e, ainda, sinais em que há uma mescla das três épocas em seu uso, os sinais em variação.

De acordo com essas características de mudança selecionamos 45 (quarenta e cinco) sinais, que apresentamos a seguir, no Quadro 2: 
Quadro 2 - Listagem das unidades léxicas selecionadas

\begin{tabular}{|l|l|l|}
\hline ADVOGADO & COBRA & LETRAS \\
\hline AGORA & COISA & MADRUGADA \\
\hline AGOSTO & COMPUTADOR & MECÂNICO \\
\hline ALEGRIA & CORES & MOTORISTA \\
\hline ALTO & CRIANÇA & NOIVO \\
\hline ANIMAIS & DAR & NUTRIÇÃO \\
\hline BANCO & DESCANSAR & PAPEL HIGIÊNICO \\
\hline BANHEIRO & DORMIR & PEIXE \\
\hline BOMBEIRO & FACULDADE & PENTE \\
\hline BONITO & FELIZ & POLICIAL \\
\hline BURRO & FOGÃO & PRÉDIO \\
\hline CADEIRA & GARÇON & RELIGIÃO ESPÍRITA \\
\hline CANETA & GELADEIRA & RESPONSÁVEL \\
\hline CAPITAL & HOSPITAL & REVISTA \\
\hline CHÁ & JULHO & VETERINÁRIO \\
\hline
\end{tabular}

Fonte: Dados da pesquisa

Os sinais do Quadro 2 foram distribuídos nas seguintes categorias: (i) mudança lexical; (ii) redução de item lexical; (iii) acréscimo de item lexical; (iv) sinais idênticos; e, (v) sinais em variação. Quanto à grafia das palavras em letra maiúscula, faz-se necessário esclarecer que, na Libras, tem sido adotada a grafia das palavras em caixa alta (glosa) como representação do sinal manual com sentido equivalente (MCCLEARY et al., 2010).

\subsection{Os participantes}

A pesquisa contou com estudantes surdos que cursavam o primeiro, o terceiro, o quinto e o sétimo períodos do curso de Letras: Libras. Selecionamos esses períodos por serem os únicos oferecidos pela instituição no momento de nossa pesquisa de campo. A despeito de haver uma variedade de surdos de outros estados e que estudam no mesmo curso, restringimos nossas entrevistas apenas aos surdos goianos e residentes em Goiânia. Totalizamos 
14 (quatorze) estudantes, sendo 8 (oito) do gênero masculino e 6 (seis) do gênero feminino, de faixas etárias diferentes, que variam entre 20 e 33 anos, todos filhos de pais ouvintes e que relataram ter aprendido Libras entre 1 e 16 anos, nas cidades de Goiânia, Anápolis, Aparecida de Goiânia, Caldas Novas, Goiás, Jaraguá, São Luís de Montes Belos e Quirinópolis.

Vale ressaltar que todos os participantes possuem fluência na Libras e a utilizam como sua principal forma de comunicação, mesmo alguns tendo adquirido a língua tardiamente.

\subsection{Procedimentos de coleta e análise dos dados}

A coleta de dados com os participantes foi precedida pela submissão ao Comitê de Ética em Pesquisa CEP da UFG que, após alguns ajustes, obteve autorização, pelo parecer $n^{\circ} 2.465 .170$, Certificado de Apresentação para Apreciação Ética - CAAE: 78911517.0.0000.5083. Somente após aprovação do Comitê iniciamos as entrevistas com os participantes.

\subsubsection{O vídeo e a entrevista}

Ao elaborarmos o questionário para a entrevista, optamos por produzi-lo em Libras (vídeo), no intuito de respeitar a especificidade linguística do nosso público-alvo e de possibilitar a interação com esse público em nossa pesquisa usando a sua primeira língua, a Libras.

O vídeo que produzimos está disponibilizado no site do YouTube e pode ser acessado pelo link: https://youtu.be/XOsEqUXpdn8. Nele está disposta a seguinte pergunta (sinalizada): "Quais sinais você utiliza para referir-se às imagens exibidas a seguir?". Logo na sequência, são apresentadas as imagens que fazem referência às unidades léxicas selecionadas como corpus deste trabaIho (cf. Quadro 2). 
A mudança lexical em Libras: um estudo preliminar em Goiás

Leandro Viana Silva • Sheila de Carvalho Pereira Gonçalves

Vale esclarecer que preferimos a utilização de imagens seguidas de suas glosas, a fim de minimizar a dubiedade entre as imagens e os sinais pretendidos, uma vez que algumas das imagens poderiam causar ambiguidade ou indecisão. As entrevistas serviram, especialmente, para validarmos a nossa hipótese de mudança, diante do uso da língua pelos falantes surdos que usam a Libras como sua principal língua. Por meio da sinalização dos surdos, comprovarmos ou refutarmos quais unidades léxicas efetivamente passaram por mudanças em suas formas.

A aplicação do questionário aconteceu da seguinte forma: cada participante foi entrevistado individualmente. O vídeo contendo o questionário e as imagens foram mostrados aos participantes, sendo computado o tempo de 5 segundos de intervalo entre as imagens. Esse intervalo foi destinado à execução dos referidos sinais pelos participantes. Todo esse processo foi filmado para fins de registro, que julgamos necessário devido à modalidade da língua de sinais, visuoespacial.

\subsubsection{Elan}

Os sinais, no primeiro momento, foram registrados em vídeo e, em seguida, na análise dos dados, contamos com o auxílio do software ELAN 5 (Eudico Linguistic Annotator), pois com ele é possível fazer anotações vinculadas a trechos exatos dos vídeos, o que nos permitiu fazer uma análise mais elaborada. As anotações são realizadas nas trilhas e podem ser definidas por cada pesquisador a quantidade que necessita utilizar. Em nossa análise, utilizamos 3 (três) trilhas para anotações: 1. Glosa; 2. Referência; e 3. Observações. Veja a seguir na Figura 6.

5 Site oficial do software: http://www.lat-mpi.eu/tools/elan/. 
A mudança lexical em Libras: um estudo preliminar em Goiás

Leandro Viana Silva • Sheila de Carvalho Pereira Gonçalves

Figura 6 - Conjunto de trilhas e transcrições

\begin{tabular}{|c|c|c|c|c|}
\hline \multirow{3}{*}{$\frac{\text { GLOSA }}{|44|}$} & $00: 00: 40.000$ & \multicolumn{2}{|c|}{$00: 00: 45.000$} & \multirow{2}{*}{$00: 00: 50.000$} \\
\hline & |BURRO & BONITO & ICOISAS & \\
\hline & & & & \\
\hline \multirow{2}{*}{ REFERÊNCIA } & ASG - CHAPLIN & CHAPLIN & |ASG & \\
\hline & & & & \\
\hline \multirow{2}{*}{ OBSERVAÇÕES } & \begin{tabular}{|l} 
Duas mãos \\
\end{tabular} & & Duas mãos & \\
\hline & & & & \\
\hline
\end{tabular}

Fonte: Software de computador ELAN (ELAN, 2018)

Na trilha 1, utilizamos para registrar as glosas correspondentes aos sinais dos vídeos. As informações, como a obra em que os sinais apareciam, ASG ou Chaplin, posicionamos na trilha 2. Já para as anotações de quantidade de mãos dos sinais e demais detalhes das sinalizações, utilizamos a trilha 3.

\subsubsection{O registro em ELiS}

Posteriormente, todos os sinais, os antigos e os atuais, foram escritos e, para isto, utilizamos o Sistema brasileiro de Escrita das Línguas de Sinais (ELiS) ${ }^{6}$, que consiste em um sistema de escrita alfabético linear, cujos caracteres são denominados visografemas. Os visografemas representam as configurações de dedos, orientações da palma, pontos de articulação e movimentos, dentre os quais estão presentes a complexidade das expressões não manuais. Esses elementos são organizados em uma estrutura própria que segue a dinâmica natural de formação dos sinais, ou seja, sua natureza cumulativa resulta em simultaneidade (BARROS, 2015).

Escolhemos esse sistema porque a estrutura dos sinais nele representada é claramente percebida. O sistema é capaz de representar as unidades mínimas dos sinais, o que possibilitou fazer uma análise mais detalhada.

Além da escrita em ELiS, para contrastar a mudança entre os sinais, apresentamos também a representação em desenho dos

6 Sistema criado pela professora Dra. Mariângela Estelita Barros, em 1998, que presenteou, a nosso ver, a língua de sinais com uma escrita própria e possibilitou o registro da língua de sinais sem a mediação de outra língua. 
sinais contidos nas duas coleções em colunas, quando possível e, ao lado destes, o sinal atual. Nos sinais antigos, utilizamos as mesmas imagens dispostas no nosso corpus e, na sequência, no sinal atual, priorizamos por utilizar nossa própria imagem para os novos registros. Ressaltamos ainda que todos os 'sinais atuais' apresentados em nossa análise são descritos no sistema ELiS e usamos parâmetros fonológicos para essa descrição, evitando, porém, descrições apenas imagéticas.

\section{Apresentação e análise dos dados}

Nesta seção, são expostos parte do resultado desta pesquisa, assim como a descrição e análise comparativa dos dados. Os resultados mostram um panorama da Libras que atravessa três épocas, a partir de registros de sinais em 1994, 2006 e 2018. Esses sinais foram categorizados em seis grupo, conforme citamos, a saber: sinais idênticos, mudança lexical, duplicação das mãos, apagamento de uma parte do sinal composto, acréscimo de itens lexicais, variação fonológica e variação lexical.

Diante dos exemplos, conforme afirmamos, elucidaremos mais detalhadamente os sinais pertencentes à categoria denominada mudança lexical, ou seja, sinais que sofreram mudanças em toda a sua forma e passaram a ter novas formas. Apresentaremos os sinais usados atualmente em contraposição aos registrados nas instituições: Chaplin e ASG. Em seguida, contrapomos os sinais atuais aos sinais que estão presentes somente no acervo do Chaplin e, por último, os sinais usados hoje em dia em oposição aos que estão disponíveis apenas na ASG.

Os sinais COR(ES) e VETERINÁRIO são exemplos que nossas pesquisas demonstraram que apresentaram mudança lexical, em contraste com as duas obras analisadas. O grupo composto por CAPITAL, FELIZ, ALEGRIA, RESPONSÁVEL e MADRUGADA são sinais que também pertencem às mudanças lexicais, mas em uma subcategoria, focada apenas nos registros do Chaplin, enquanto 
A mudança lexical em Libras: um estudo preliminar em Goiás

Leandro Viana Silva • Sheila de Carvalho Pereira Gonçalves

que CRIANÇAS, LETRAS e NUTRIÇÃO demonstraram mudanças lexicais nos registros da ASG. Esclarecemos que selecionamos aleatoriamente exemplos desse grupo que são detalhados a seguir.

\subsection{Mudança lexical: chaplin, ASG VERSUS hoje}

O sinal atualmente utilizado pelos surdos goianos para representar COR(ES) apresenta efetivamente uma mudança em toda sua forma, além da nítida quantidade (redução) de itens presentes em sua produção, entre as duas formas antigas (7a e 7b) comparadas à forma utilizada hoje em dia (7c). Notamos que, esse sinal, no primeiro documento, foi registrado com os seguintes itens VERMELHO^VARI@S7 (sinal monomanual), passando a ser representado, no segundo, por VERMELHO^VARI@S (sinal bimanual) e em nossos resultados, na imagem (7c), representado por outra forma que se difere totalmente das anteriores. Observe as ilustrações da Figura 7.

Figura 7 - Mudança lexical do sinal COR(ES)

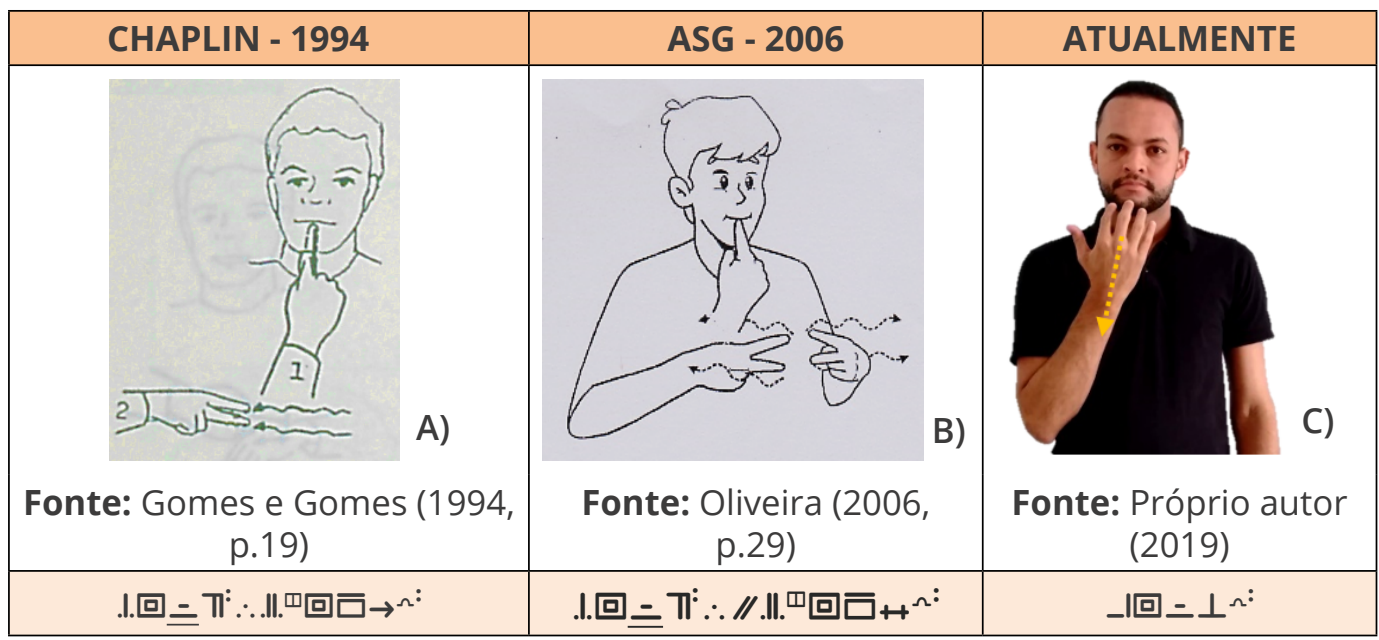

De acordo com Nascimento e Correia (2011), uma hipótese de reconstituição diacrônica para esse sinal é o fato de o sinal VERMELHO ser produzido próximo aos lábios, isto, na visão das autoras, teria atraído a produção do sinal VARI@S também para a proxi-

7 Para notação em glosa utiliza-se o símbolo @, quando não há marcação de gênero e o símbolo ^, entre cada item lexical, em casos de sinais compostos. 
midade dos lábios e, mais adiante, teria distendido toda a mão, resultando na forma (7c) $\perp^{\prime}$ 回 $=\perp^{\wedge:}$ usada atualmente.

As representações dispostas para o sinal COR(ES), vistas anteriormente, apresentam duas mudanças para o sinal. Primeiro, considerando o sinal (7a) .1.回三 $\pi^{\ddagger} \therefore . .1$. 回回口 $\rightarrow^{n:}$ em contraste com (7b)

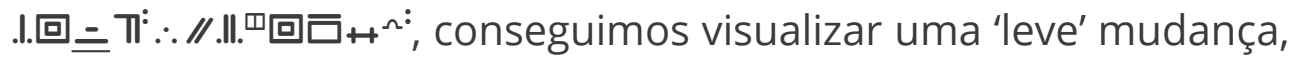
a presença de /III, símbolo gráfico que indica 'sinal bimanual simétrico'. Em outras palavras, o segundo item lexical (VARI@S) do sinal, antes produzido com apenas uma mão, passa pelo processo de duplicação das mãos (ver XAVIER, 2014).

Na representação usada atualmente, em (7c) _l回 $=\perp^{n \text { : }}$, observamos a mudança em toda a forma do sinal, porém, sendo ainda realizada no mesmo Ponto de Articulação (PA), /二/ 'boca' e, neste último, sem o uso de /_/, sublinhado que representa o contato do sinal, e a Configuração de Dedo (CD) que antes era /.I./, 'polegar fechado, dedo indicador estendido contínuo à palma e demais dedos fechados', passando a ser usada hoje com /_l/, 'polegar estendido perpendicularmente ao lado da palma e demais dedos estendidos contínuos à palma'.

A seguir, ao analisarmos o sinal VETERINÁRI@, vimos que este também passa pelo fenômeno da mudança lexical, ao apresentar uma nova forma para designá-lo. Na Figura (8a), temos a composição dos itens MÉDIC@^CACHORRO^VARI@S, respectivamente, para representar o sinal VETERINÁRI@. Logo, na Figura (8b), vimos que o sinal é composto apenas por MÉDIC@^CACHORRO. E, por último, em (8c), expresso por uma nova forma. Veja, na Figura 8, a mudança lexical deste sinal. 
Figura 8 - Mudança lexical do sinal VETERINÁRI@

\begin{tabular}{|l|l|l|}
\hline CHAPLIN - 1994 & ASG - 2006 \\
\hline
\end{tabular}

Na trajetória do sinal VETERINÁRI@, primeiramente produzido

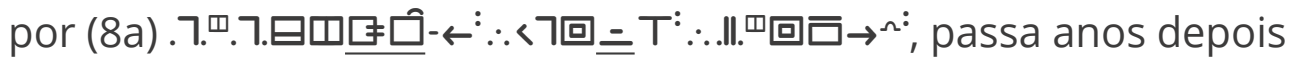

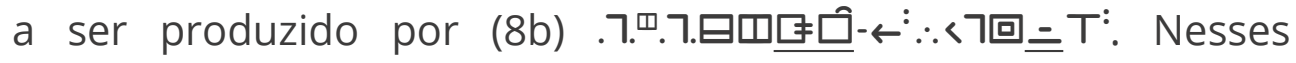
dois primeiros casos, notamos que o item lexical [..1. 回回血 $\rightarrow^{n}$ ] VARI@S, com o passar do tempo se perdeu, e as demais formas, MÉDIC@^CACHORRO, se mantiveram. Atualmente, os surdos usam outra (nova) forma para significar o referido sinal, conforme descrito em (8c) .7. ...1.

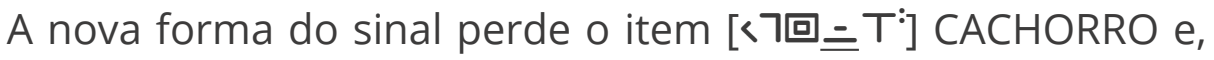
recebe por meio de empréstimo a letra ' $V$ ' (vê), que corresponde à inicial da palavra 'veterinário(a)', passando, evidentemente, por adaptação apropriada pela língua de sinais. Este caso de empréstimo, para Nascimento e Correia (2011, p. 66), é bastante comum nas línguas de sinais, em que "por meio do empréstimo apenas da inicial da palavra da língua oral, [passa a ser] totalmente adaptada e apropriada pela língua de sinais receptora, para a articulação do [novo] item lexical". Deste modo, o sinal antes expresso por composição, assume uma nova forma, perdendo assim as características de sinal composto. Segundo Nascimento e Correia (2011, p. 69), o processo de assimilar lexias complexas, tornando-as itens lexicais únicos, é visto como tendência dos falantes da Libras. Em 
outros termos, esse processo "é o tipo de tendência, no qual os sinais compostos se transformam para unitários" (DINIZ, 2010, p. 92).

Ao observarmos a transição do sinal VETERINÁRI@, vimos que ao perder os itens 'CACHORRO' e 'VARI@S', o item MEDIC@,

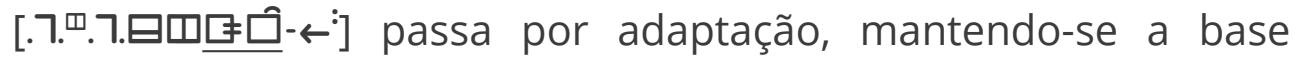
da mão passiva, /.7. $\%$ / 'polegar fechado, dedo indicador curvo e demais dedos fechados', com / $\boxminus /$, 'palma para baixo', realizado na /E/ 'articulação dos dedos', com /-/ 'ausência de movimento' e, modificando-se a mão ativa de /.7./ 'polegar fechado, dedo indicador curvo e demais dedos fechados', com / $\square$ / 'palma para a medial', com ponto de articulação na /므/ 'ponta dos dedos' e, com / $\%$ movimento 'para a esquerda', para /.II./ 'polegar fechado, dedo indicador e médio estendido contínuo à palma e demais dedos fechados', com / $\mathbf{\square} /$ 'palma para frente', ponto de articulação na /므/ 'lateral dos dedos' e, com / $\leftarrow$ / 'movimento 'para a esquerda'.

\subsection{Mudança lexical: Chaplin versus hoje}

Nesta subcategoria estão reunidas apenas as mudanças lexicais relacionadas aos registros do Chaplin, as quais vemos a seguir. De acordo com as características desta subcategoria, a análise comparativa nos permitiu selecionar os seguintes sinais: CAPITAL, FELIZ, ALEGRIA, RESPONSÁVEL e MADRUGADA.

Na mudança ocorrida no sinal CAPITAL, podemos observar que o sinal antes era expresso pela composição de dois itens lexicais, LUGAR^PRINCIPAL e, contrapondo o primeiro caso, temos atualmente uma nova forma para representá-lo, ou seja, houve uma mudança completa em sua forma. Vejamos tal mudança na Figura 9, a seguir. 
Figura 9 - Mudança lexical do sinal CAPITAL

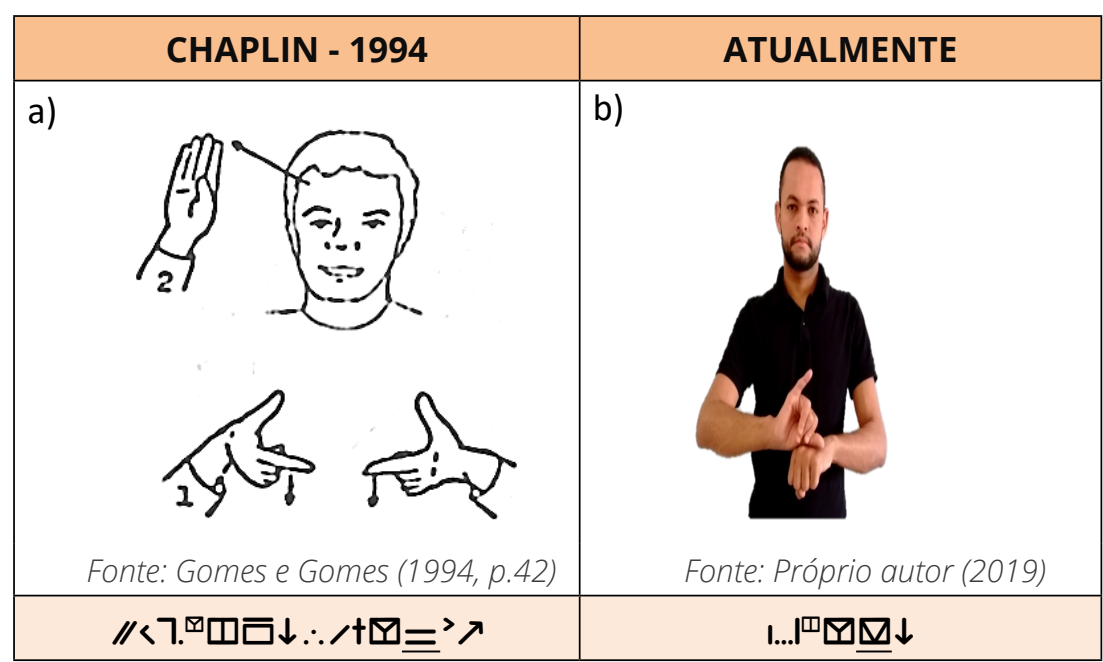

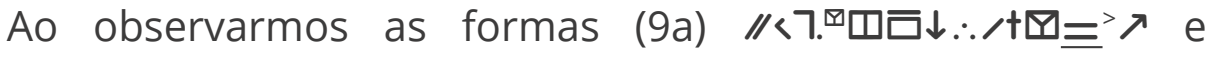
(9b) 1....'四旦 $\downarrow$, logo temos a impressão visual da manifestação do fenômeno da mudança linguística, quando visualizamos o comprimento da escrita de ambos os sinais. Vimos que a representação de 1994 era constituída de um sinal composto que, ao passar pela mudança em seu léxico, não carrega, nesse caso, nenhum traço dos itens anteriores.

Segundo Lima e Rezende (2016), os sinais constituídos por dois itens lexicais têm tendência a reduzirem sua composição a um único item, e destacam que, muitas vezes, nessa mudança as características de composição dos dois itens que formavam o sinal anterior não são mantidas. Desse modo, torna-se evidente o distanciamento entre um sinal e outro. Ressaltamos ainda que a arbitrariedade da nova forma não nos permitiu identificar suas motivações.

Apresentamos detalhadamente como o sinal CAPITAL é sinalizado, através da ELiS: mãos com /....I/ 'polegar estendido paralelamente ao lado da palma, dedos indicador, médio e anelar fechados e dedo mínimo estendido contínuo à palma', /四/ 'palma para 


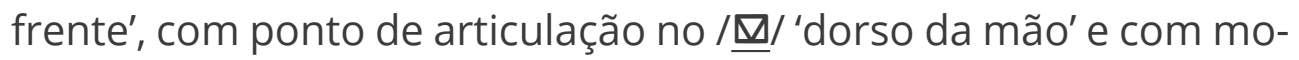
vimento / $\downarrow /$ 'para baixo'.

Logo a seguir apresentamos a forma usada atualmente para o sinal ALEGRE. O sinal caracterizado como bimanual, ao passar por mudanças em sua forma, ainda permanece com sua realização feita com ambas as mãos. No entanto, todos os demais parâmetros são modificados, exceto a CD. Observe, na Figura 10, a seguir.

Figura 10 - Mudança lexical do sinal ALEGRE

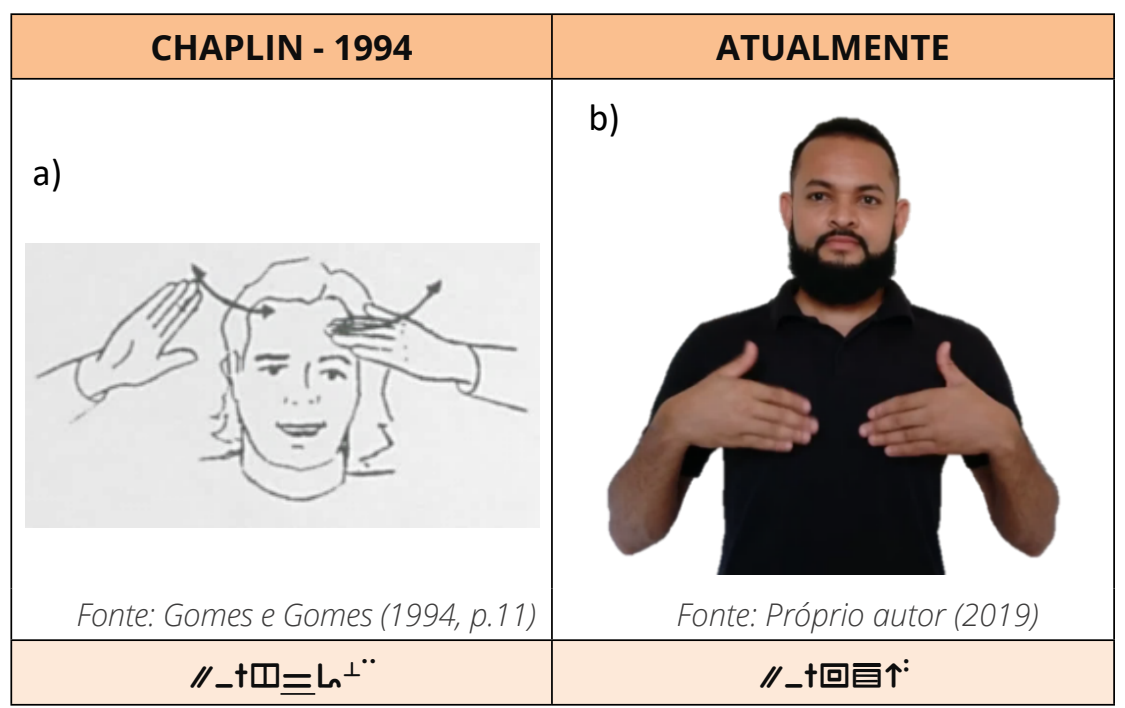

Todos os participantes da pesquisa apresentaram, sem hesitação, a forma (10b) /_t回百个: , mostrando assim o desuso da forma (10a) " / $+\mathrm{t} \Phi=\mathrm{L}^{\perp}{ }^{\perp}$. O sinal utilizado hoje carrega semanticamente o mesmo ponto de articulação usado em vários outros sinais que também expressam emoção/sentimento/estado, na região/亘/ do 'tórax', por exemplo, ÓDIO, RAIVA, AMOR, AUTOESTIMA, ANSIEDA$D E$, CORAGEM etc.

Notamos que o sinal (10b) //_t回百个:, carrega a mesma configuração manual do sinal anterior, ou seja, ambos os sinais possuem as mãos com /_t/'polegar estendido perpendicularmente ao lado da palma e demais dedos estendidos contínuos à palma e unidos', além de serem / /// 'bimanuais'. Ademais, a nova forma apresenta 
distinções como a /回/ 'palma para trás', o ponto de articulação do sinal /厚/ no 'tórax' e o movimento / $\uparrow /$ 'para cima', enquanto que a forma antiga é composta de / $\mathbf{\square} /$ 'palma para medial', com ponto de articulação / $/$ /, em contato com a 'testa' e com movimento de $/ \mathrm{L}^{\perp}$ “/ 'girar o antebraço, para frente' alternadamente.

Na sequência, veremos os resultados da análise do sinal FELIZ. A sua primeira representação é (11a) _t'回百 $\odot$, sinalizada na região /百/ do 'tórax' carrega semanticamente o mesmo ponto de articulação usado em vários outros sinais, que expressam emoção/sentimento/estado, como mencionamos anteriormente. No entanto, mesmo traços com forte carga semântica não são, pelo que podemos observar, restrições para que os sinais não sejam submetidos à mudança lexical. Vejamos, a seguir, na Figura 11.

Figura 11 - Mudança lexical do sinal FELIZ

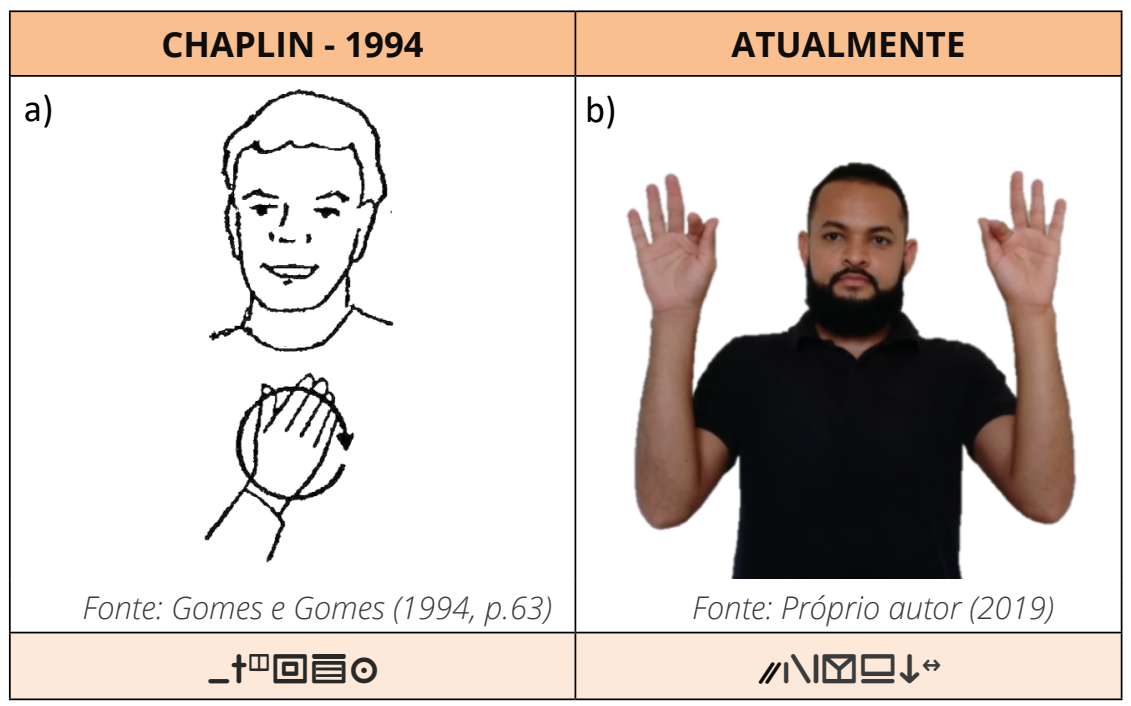

Ao observarmos as descrições de (11a) _t田回百 $\odot$ e (11b) " N⿴囗十므 $\downarrow$, logo percebemos o distanciamento entre cada uma. A forma apresentada na obra de 1994 não foi encontrada em nenhuma das sinalizações dos participantes. O contrário da forma de (11b) que foi realizada unanimemente entre os surdos. 
A mudança lexical em Libras: um estudo preliminar em Goiás

Leandro Viana Silva • Sheila de Carvalho Pereira Gonçalves

Devido à forma usada na representação do sinal (11a) _t田回百 $\odot$ ser totalmente idêntica ao sinal usado na LSF8, acreditamos que houve, nesse caso, um empréstimo linguístico, comportamento comum nas línguas. No entanto, na forma (11b) //N四므 $\downarrow$, identificamos a influência do processo de 'importação' da letra inicial da palavra (NASCIMENTO; CORREIA, 2011), como vimos anteriormente no exemplo de VETERINÁRI@ (Figura 8). Desse modo, utiliza-se a configuração manual correspondente à letra ' $F$ ' (efe) do nosso alfabeto para execução do sinal FELIZ.

O sinal FELIZ é constituído por / /// 'ambas as mãos', com /N// 'polegar estendido paralelamente ao lado da palma, dedo indicador estendido inclinado à frente da palma e demais dedos estendidos contínuos à palma', com / $\square /$ / 'palmas para frente', realizado no /므/ 'espaço à frente do rosto' e com movimentos $/ \downarrow \leftrightarrow /$ 'para baixo e para a direita e esquerda'.

Na sequência, o último sinal dessa subcategoria, é o sinal RESPONSÁVEL. Percebemos que o sinal, em sua mudança, permanece com a mesma configuração manual, porém sofre alteração nos demais parâmetros, como podemos observar, a seguir, na Figura 12.

Figura 12 - Mudança lexical do sinal RESPONSÁVEL

\begin{tabular}{|c|c|}
\hline CHAPLIN - 1994 & ATUALMENTE \\
\hline a) & b \\
\hline Fonte: Gomes e Gomes (1994, p.12) & Fonte: Próprio autor (2019) \\
\hline X. $\square \equiv \perp$ & $\mathbb{Z}$.X.回曰血 ${ }^{L<\downarrow}$ \\
\hline
\end{tabular}

8 De acordo com Le dictionnaire vivant en langue des signes. Disponível em: https://www.elix-Isf.fr/?lang=fr Acesso em: 22 out. 2018. 
A mudança lexical em Libras: um estudo preliminar em Goiás

Leandro Viana Silva • Sheila de Carvalho Pereira Gonçalves

Nesses sinais ocorre mais uma vez o empréstimo das letras do alfabeto para a criação do sinal. Assim sendo, notamos que em ambas as épocas os sinais são "motivados pela 'importação' da letra inicial da palavra equivalente em língua portuguesa. Essa letra será a CM utilizada para a articulação do item designado" (NASClMENTO; CORREIA, 2011, p. 67). A localização do sinal, pode ter sido motivada pela referência que se faz ao 'peso' da responsabilidade que se 'carrega nos ombros'.

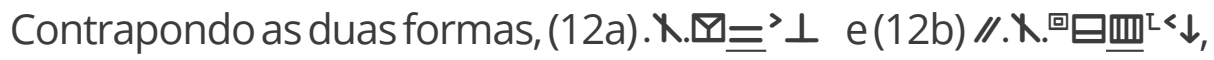
vimos como traços mais relevantes a permanência da $C D$, ou seja, $/ . X$./ 'polegar fechado, dedo indicador estendido contínuo à palma, dedo médio estendido perpendicularmente à frente da palma e demais dedos fechados' e a alteração do sinal antes monomanual (12a) e agora bimanual (12b).

\subsection{Mudança lexical: ASG Versus hoje}

Esta subcategoria é limitada somente às mudanças lexicais relacionadas aos registros da ASG. Desse modo, conheceremos, a seguir, os sinais CRIANÇAS, LETRAS e NUTRIÇÃO, e suas respectivas mudanças que os classificaram como pertencentes a este grupo.

$\mathrm{Na}$ análise do sinal CRIANÇAS, vimos que o sinal muda de um para dois itens lexicais. Essa mudança pode ser percebida nas ilustrações e nas escritas de cada sinal. Vejamos, na Figura 13, as for-

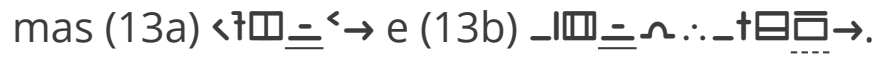


Figura 13 - Mudança lexical do sinal CRIANÇAS

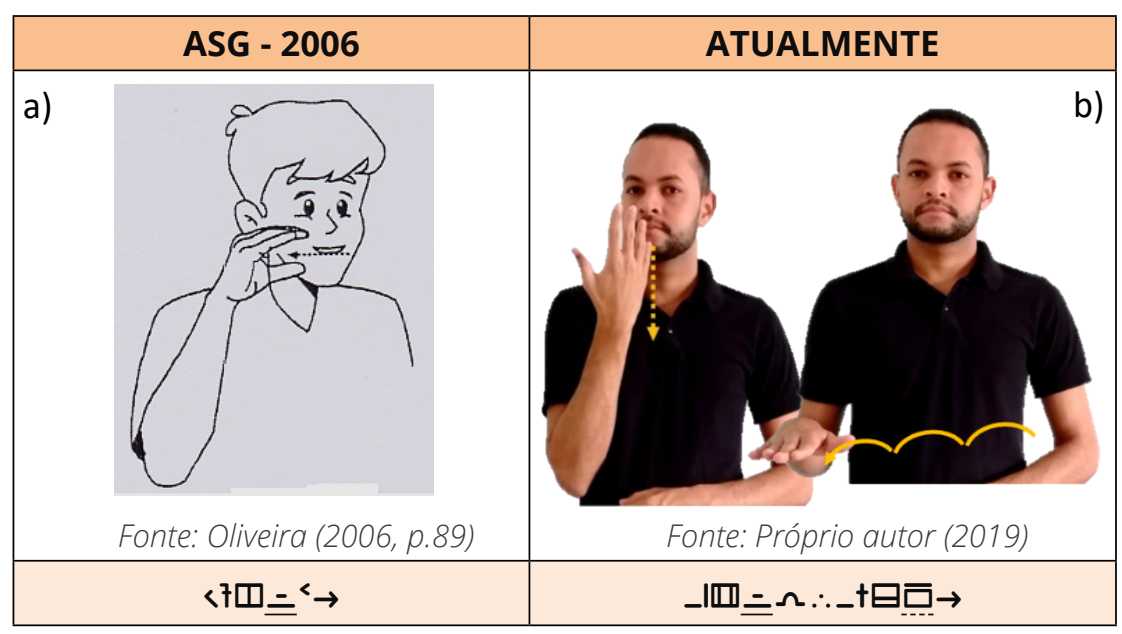

O sinal expresso em (13a) por $<7 \mathbb{W}^{<} \rightarrow$, tempos depois tem

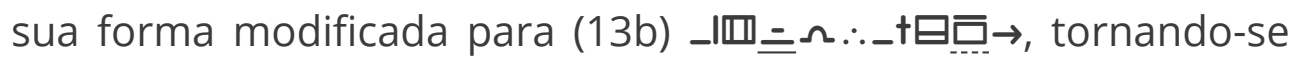
extinta sua forma anterior. Destacamos que um dos participantes de nossa pesquisa, diferente dos demais, sinalizou apenas o

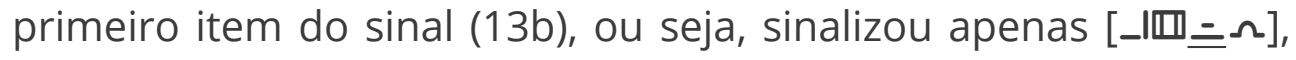
sem a marcação de número [-†日[그]; o que não deixou de ser compreensível, pois, a nosso ver, o primeiro item possui maior carga semântica que o segundo. Vale destacar ainda, que na forma (13a) $<7 \mathbb{W}^{2} \rightarrow$ e no primeiro item exposto em (13b) [-I四三 $\Omega$ ] $\therefore$ 十田 $\rightarrow$, o ponto de articulação do sinal, isto é, na /三/ 'boca' ainda permanece.

Vejamos agora como é sinalizado o sinal CRIANÇAS: mão com /_I/ 'polegar estendido perpendicularmente ao lado da palma e demais dedos estendidos contínuos à palma', /四/ 'palma para a distal', localizado na / / 'boca' e com movimento de / $\Omega /$ 'tamborilar de dedos', / $\therefore$ / 'composto' com mão com /_t/ 'polegar estendido perpendicularmente ao lado da palma e demais dedos unidos e estendidos contínuos à palma', com / $\boxminus /$ 'palma para baixo', realizado no /므/ 'espaço neutro' e com movimento / $\rightarrow$ / 'para a direita'.

Em seguida, analisaremos o sinal LETRAS que, não diferente dos demais, teve também uma mudança em seu léxico. O sinal an-

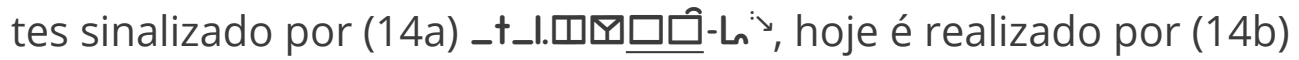
/I_I.日血血 ${ }^{2}-\downarrow ;$, como pode ser observado, na Figura 14. 
Figura 14 - Mudança lexical do sinal LETRAS

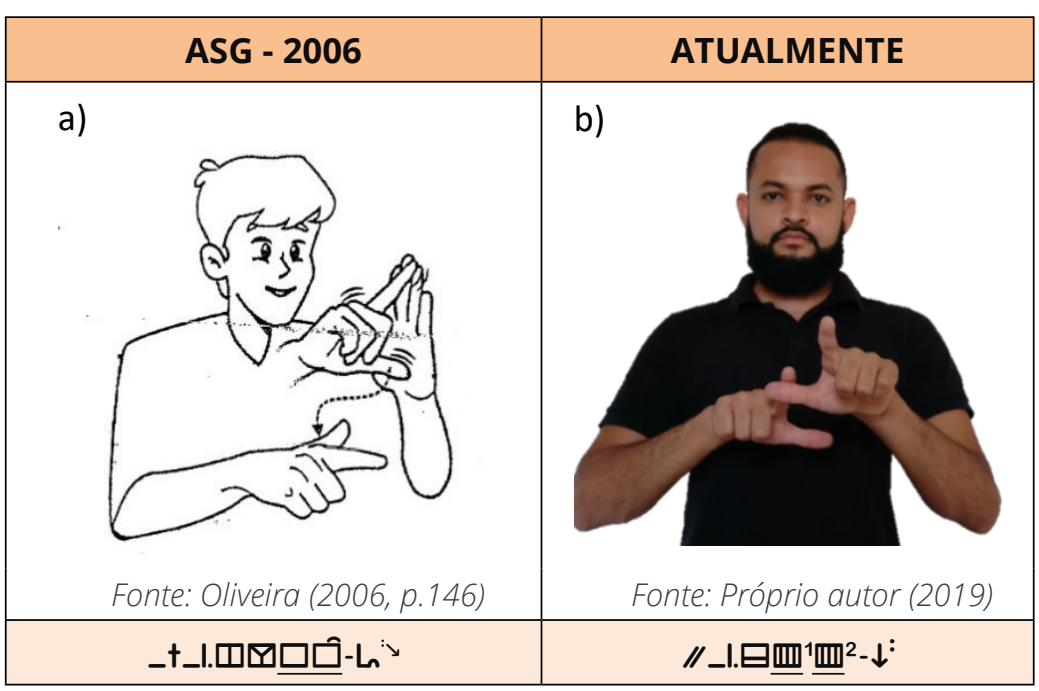

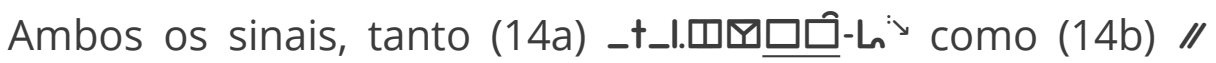
-1.日回 ${ }^{1}{ }^{2}-\downarrow$; , são bimanuais, realizados com ambas as mãos, porém um é assimétrico e outro simétrico. Notemos que nas duas formas do sinal é conservada a 'importação' da letra inicial da palavra correspondente na língua portuguesa (NASCIMENTO; CORREIA, 2011). Assim, utiliza-se a configuração manual correspondente à letra 'L' (ele) do nosso alfabeto para execução do sinal LETRAS.

Para o sinal LETRAS, usado atualmente, a leitura de sua escrita é: /I// 'ambas as mãos' com /_l./ 'polegar estendido perpendicularmente ao lado da palma, dedo indicador estendido contínuo à palma e demais dedos fechados', / $\boxminus$ / 'palma para baixo', com ponto de articulação na / $\underline{\underline{m}}^{1} \underline{\underline{m}}^{2} /$ mão esquerda 'dedo polegar' e mão direita 'dedo indicador' e, por fim, com /- $\downarrow$ / 'ausência de movimento' da mão esquerda e movimento da mão direita 'para baixo'. Passemos às nossas considerações finais.

\section{Apontamentos finais}

Nesta pesquisa, buscou-se realizar um estudo sobre a mudança lexical da Libras, a partir da seleção de sinais dispostos em antigos registros, retirados de materiais didáticos de duas instituições, 
sendo contrapostos a formas atualmente sinalizadas por surdos goianos. Limitada às obras de duas grandes instituições muito (re) conhecidas no estado de Goiás, pelo ensino e difusão da Libras, - Sistema Educacional Chaplin, primeira escola a ensinar Libras no estado, e a Associação dos Surdos de Goiânia (ASG), a pesquisa contou, também, com a participação de quatorze surdos, para confirmação das atuais representações dos sinais.

Ao final da análise, podemos finalmente concluir que todos os sinais compostos, presentes nessa categoria, tiveram alterações na quantidade de itens de suas representações, como os sinais com três itens (VETERINÁRI@ e NUTRIÇÃO) que são representados em suas novas formas com apenas um item e os sinais com dois itens (COR(ES) e CAPITAL) que passaram também para representações de um item. Esse processo parece realmente ser um tipo de tendência na Libras, como afirma Diniz (2010, p. 92), que "os sinais compostos se transformam para unitários", porém não vimos tendência de casos opostos a esses, de sinais unitários se transformando para sinais compostos.

Identificamos um único caso com a ocorrência inversa ao apresentado como tendência pela autora. O sinal CRIANÇAS, que dispõe de um único item lexical e passa a ser representado atualmente com dois itens. Mas nesse tipo de ocorrência parece não haver uma regularidade.

Nossa análise nos permitiu identificar, em alguns casos, traços de motivações por detrás dos signos, tanto dos sinais já registrados nas obras analisadas como nos "novos" sinais apresentados pelos surdos, traços que vão desde a influência da língua portuguesa a aspectos mais evidentes na representação dos signos.

A partir das representações feitas com a ELiS, verificamos o altíssimo grau de funcionalidade e que, de fato, é uma escrita totalmente eficiente para o registro dos sinais. Por meio dessa escrita, conseguimos realizar uma análise cuidadosa dos dados, que nos possibilitou identificar as variações e as mudanças linguísticas.

Esperamos que esta pesquisa, além de organizar informações sobre as mudanças dos sinais, possa contribuir com estudiosos, 
A mudança lexical em Libras: um estudo preliminar em Goiás

Leandro Viana Silva • Sheila de Carvalho Pereira Gonçalves

especialmente da área da Linguística da Libras, e ainda servir de estímulo para mais pesquisas na área da variação ou mudança linguística nessa língua.

Pretendemos também contribuir para os cursos de formação de professores de Libras, bem como estimular o surgimento de mais pesquisas dessa natureza, uma temática que, a nosso ver, pode ser mais explorada nas aulas.

\section{Referências}

BARROS, M. E. ELiS: sistema brasileiro de escrita das línguas de sinais. Porto Alegre: Penso, 2015.

CAMACHO, R. A variação lingüística. In: Subsídios à proposta curricular de Língua Portuguesa para o $1^{\circ}$ e $2^{\circ}$ graus. Secretaria da Educação do Estado de São Paulo, 1988.

CAMPELLO, A. R. S. A constituição histórica da Língua de Sinais Brasileira: século XVIII a XXI. Revista Mundo \& Letras, José Bonifácio/ SP, v. 2, p. 8-25, 2011.

CASTRO JÚNIOR, G. Variação linguística em Língua de Sinais Brasileira: foco no léxico. 2011. 123 f. Dissertação (Mestrado) - UnB/ Instituto das Letras, Departamento de Linguística, Português e Línguas Clássicas - LIP Portuguesa, Brasília, 2011.

CHAGAS, P. A mudança linguística. In: FIORIN, J. L. et al (Org.). Introdução à Linguística I: objetos teóricos. 6. ed. São Paulo: Contexto, 2012. p. 141-164.

DINIZ, H. G. A história da Língua de Sinais Brasileira (Libras): um estudo descritivo de mudanças fonológicas e lexicais. 2010. $113 \mathrm{f}$. Dissertação (mestrado) - Centro de Comunicação e Expressão. Programa de Pós-Graduação em Linguística, Universidade Federal de Santa Catarina, Florianópolis. 2010.

ELAN (Versão 5.2) [Software de computador]. (2018, 04 de abril). Nijmegen: Instituto Max Planck de Psicolinguística. Obtido em: https://tla.mpi.nl/tools/tla-tools/elan/ 
A mudança lexical em Libras: um estudo preliminar em Goiás

Leandro Viana Silva • Sheila de Carvalho Pereira Gonçalves

KARNOPP, L. B. Fonética e fonologia. Apostila do curso de LetrasLibras-licenciatura e bacharelado. 2008.

KOGUT, M. K. As Descrições Imagéticas na transcrição e leitura de um texto em SignWriting. 2015. 161f. Dissertação (mestrado) Centro de Comunicação e Expressão. Programa de Pós-Graduação em Linguística, Universidade Federal de Santa Catarina, Florianópolis. 2015. LIMA, H. J. de \& REZENDE, T. F. Mudanças Lexicais na Língua de Sinais Brasileira. In: $13^{\circ}$ Congresso de Pesquisa, Ensino e Extensão da Universidade Federal de Goiás - CONPEEX, 2016, Goiânia. Anais do XIII CONPEEX. Goiânia: Universidade Federal de Goiás, 2016. p. 2864-2869. MCCLEARY, L. E. et al. Descrição de línguas sinalizadas: a questão da transcrição dos dados. Alfa: Revista de Linguística (UNESP. São José do Rio Preto. Impresso). v. 54. p. 265-289, 2010.

NASCIMENTO, S. P. F. \& CORREIA, M. Um olhar sobre a morfologia dos gestos. Lisboa: Universidade Católica Editora, 2011.

SCHMITT, D. A história da língua de sinais em Santa Catarina: contextos sócio-históricos e sociolinguísticos de surdos de 1946 a 2010. 2013. 228f. Tese (Doutorado) - Universidade Federal de Santa Catarina, Centro de Comunicação e Expressão. Programa de Pós-Graduação em Linguística, Florianópolis, 2013.

WEINREICH, U. et al. I Fundamentos empíricos para uma teoria da mudança linguística. Tradução de Marcos Bagno. São Paulo: Parábola, 2006.

XAVIER, A. N. Uma ou duas? Eis a questão!: um estudo do parâmetro número de mãos na produção de sinais da língua brasileira de sinais (Libras). 2014. 178f. Tese (Doutorado) - Universidade Estadual de Campinas, Instituto de Estudos da Linguagem. Instituto de Estudos da Linguagem, Campinas, 2014.

ZANCANARO JUNIOR, L. A. \& BIELESKI, D. O processo de mudanças na língua brasileira de sinais em Santa Catarina: uma análise comparativa. Revista Encontros de Vista. v. 1, p. 60-73, 2011. 